\title{
Predictor variables for a half marathon race time in recreational male runners
}

This article was published in the following Dove Press journal:

Open Access Journal of Sports Medicine

I August 20| |

Number of times this article has been viewed

\section{Christoph Alexander Rüst ${ }^{\prime}$ \\ Beat Knechtle ${ }^{1,2}$ \\ Patrizia Knechtle ${ }^{2}$ \\ Ursula Barandun' \\ Romuald Lepers ${ }^{3}$ \\ Thomas Rosemann' \\ 'Institute of General Practice and Health Services Research, University of Zurich, Zurich, Switzerland; ${ }^{2}$ Gesundheitszentrum St Gallen, St Gallen, Switzerland; ${ }^{3}$ INSERM U887, University of Burgundy, Faculty of Sport Sciences, Dijon, France}

Correspondence: Beat Knechtle

Facharzt FMH für Allgemeinmedizin, Gesundheitszentrum St Gallen,

Vadianstrasse 26,

900I St Gallen, Switzerland

Tel $+4|07| 2268282$

Fax +4I $07 \mid 2268272$

Email beat.knechtle@hispeed.ch

\begin{abstract}
The aim of this study was to investigate predictor variables of anthropometry, training, and previous experience in order to predict a half marathon race time for future novice recreational male half marathoners. Eighty-four male finishers in the 'Half Marathon Basel' completed the race distance within (mean and standard deviation, SD) 103.9 (16.5) min, running at a speed of $12.7(1.9) \mathrm{km} / \mathrm{h}$. After multivariate analysis of the anthropometric characteristics, body mass index $(r=0.56)$, suprailiacal $(r=0.36)$ and medial calf skin fold $(r=0.53)$ were related to race time. For the variables of training and previous experience, speed in running of the training sessions $(r=-0.54)$ were associated with race time. After multivariate analysis of both the significant anthropometric and training variables, body mass index $(P=0.0150)$ and speed in running during training $(P=0.0045)$ were related to race time. Race time in a half marathon might be partially predicted by the following equation $\left(r^{2}=0.44\right)$ : Race time $(\min )=72.91+3.045 *$ (body mass index, $\left.\mathrm{kg} / \mathrm{m}^{2}\right)-3.884 *$ (speed in running during training, $\mathrm{km} / \mathrm{h}$ ) for recreational male runners. To conclude, variables of both anthropometry and training were related to half marathon race time in recreational male half marathoners and cannot be reduced to one single predictor variable.
\end{abstract}

Keywords: anthropometry, body fat, skin-folds, training, endurance

\section{Introduction}

Running is a popular sports discipline and can be performed over various distances. ${ }^{1,2}$ Different physiological, anthropometric, and training characteristics seem to influence running performances depending upon the length and the duration of the performance. ${ }^{3-6}$ Regarding the anthropometric characteristics, the relationship of skin-fold thickness to running performance has been discussed for a number of years. Hagan et al reported in 1981 that the sum of seven skin-folds was correlated to a marathon performance time. ${ }^{7}$ Bale et al showed in 1986 that the total sum of skin-folds, the type and the frequency of training, and the running experience such as the number of years running were the best predictors of running performance and success over the $10,000 \mathrm{~m}$ distance. ${ }^{8}$ A correlation of thicknesses of selected skin-folds with running performance has been reported for top class male and female runners of distances from $100 \mathrm{~m}$ to $10,000 \mathrm{~m}$ and the full marathon distance. ${ }^{9,10}$ High correlations were found for the front thigh and medial calf skin-fold with both $1500 \mathrm{~m}$ and $10,000 \mathrm{~m}$ race times in male runners. ${ }^{9}$ Other anthropometric characteristics related to running performance apart from selected skinfold thicknesses were the sum of skin-folds, ${ }^{11,12}$ body mass, ${ }^{13-15}$ body mass index,${ }^{11,14,16}$ percent body fat, ${ }^{11,14,17}$ and the circumference of upper arm. ${ }^{14,15,18}$ These associations were mainly found in ultra-marathoners. 
Apart from anthropometry, the volume and intensity of training sessions have also been reported to influence running performance. Bale et al showed that elite runners who averaged higher training frequencies, a higher weekly training volume and had more running experience performed better over the $10,000 \mathrm{~m}$ distance. ${ }^{8}$ In marathon finishers, the longest distance covered per training session was related to race time. ${ }^{19}$ In female marathoners, the number of training sessions per week and the number of years training were the best predictors of race performance at the marathon distance..$^{20}$ Scrimgeour et al reported that runners who trained for more than $100 \mathrm{~km}$ per week had significantly faster race times over $10 \mathrm{~km}$ to $90 \mathrm{~km}$ than athletes covering less than $100 \mathrm{~km} .{ }^{21}$ When the training of marathoners was analyzed in detail, several parameters such as training session days, number of total training sessions, total kilometers covered during a training session, average number of kilometers covered per training session, longest mileage covered per training session, the total of training minutes, maximal kilometers ran per week, average kilometers covered per week and the average kilometers covered per day were related to marathon performance times. ${ }^{7,19,22}$ Hewson and Hopkins described a correlation between the weekly duration of continuous running at moderate intensity and the performance of runners specializing in longer distances. ${ }^{23}$ The intensity of training sessions was also important regarding race performance. Peak running velocity was highly related to a $5000 \mathrm{~m}$ run time for both male and female athletes. ${ }^{24}$

The lower thickness of the skin-folds of the lower limbs in high level runners seems to be due to training. Legaz and Eston investigated the change in skin-fold thicknesses across 3 years in high-level runners. ${ }^{10}$ Training resulted in a significant increase in performance and in a decrease in the sum of six skin-folds, abdominal, front thigh, and medial calf skin-folds. In a sample of 24 male and female endurance runners, they described a significant association between the decrease in front thigh skin-fold thickness and improvement in performance due to training. ${ }^{10}$

This background shows that the relationship of both skin-fold thicknesses and training variables to race performance has been investigated for running distances from $100 \mathrm{~m}$ to the full marathon length for male and female top athletes, but not for recreational male runners over the half marathon distance. In general, the largest group of competitors in half marathons and marathons are recreational runners, not professional runners. ${ }^{25}$ Therefore, the question whether there were relationships between both selected skin-fold thicknesses and training variables with a half marathon race performance for male recreational runners can be raised.

The first aim of this study was to investigate which basic variables of physical characteristics, training, or previous experience were related to a half marathon race time in recreational male runners. Based on the existing literature, it was hypothesized that variables of both anthropometry and training would be related to a half marathon race time in recreational runners. We intended to create an equation to predict a half marathon race time for future novice male half marathoners, based upon basic measurements of anthropometry and training. An equation based upon basic measurements of anthropometry and training might help future half marathoners to better prepare for the first half marathon. The second aim was to investigate potential associations between skin-fold thicknesses and training characteristics such as volume and running speed. A significant association would help the runners to better plan their training with either high volume or fast training sessions.

\section{Materials and methods Subjects and race}

The organizer of the 'Half Marathon Basel' in Basel, Switzerland, contacted all the male participants in the 2010 race via a separate newsletter, 3 months before the race, in which they were asked to participate in the study. A total of 691 male athletes started the 'Half Marathon Basel', from which 84 male starters volunteered to participate in the investigation. These athletes were all recreational and nonprofessional athletes, where a professional athlete was defined as a person who earns his livelihood with only the financial support of a sponsor, plus trophy money. Of the study group, all 84 subjects finished the 'Half Marathon Basel' within the time limit of 2.3 hours. The study was approved by the Institutional Review Board of the Canton of St Gallen, Switzerland. The subjects were informed of the experimental procedures and gave their informed written consent. The 'Half Marathon Basel' took place on 12th September 2010, in the City of Basel, Switzerland. The athletes started at $11 \mathrm{am}$ and had to run one flat lap on asphalt. The weather was fine and dry. The temperature was $13^{\circ} \mathrm{C}$ at the start and the relative humidity was at $63 \%$. The organizer provided nutrition and drinks at eight aid stations.

\section{Measurements and calculations}

Before the start of the race body mass, body height, and thicknesses of skin folds were measured. Body mass was measured 
to the nearest $0.1 \mathrm{~kg}$ using a Beurer ${ }^{\circledR} \mathrm{BF} 15$ scale (Beurer $\mathrm{GmbH}$, Ulm, Germany). Body height was measured to the nearest $1 \mathrm{~cm}$ using a stadiometer. Body mass index $\left(\mathrm{kg} / \mathrm{m}^{2}\right)$ was calculated from body mass and body height. Skin-fold thicknesses were measured by the same investigator at the following eight sites: pectoral, triceps, mid-axilla, subscapular, abdominal, suprailiacal, front thigh, and medial calf. Skin-fold data were obtained using a skin fold caliper (GPM-Hautfaltenmessgerät, Siber and Hegner, Zurich, Switzerland) and recorded to the nearest $0.2 \mathrm{~mm}$. The measurements were made three times on the right side of the body and the means were analyzed. Readings were performed 4 seconds after applying the caliper to ensure the reliability of the skin-fold measurements. ${ }^{26}$ An intra-tester reliability check was conducted on 27 male runners prior to testing. Intra class correlation (ICC) within the two judges was excellent for all anatomical measurement sites $(\mathrm{ICC}>0.9) .{ }^{27}$ Percent body fat was calculated using the following formula according to Ball et al with percent body fat $=0.465+0.180 *(\Sigma 7 \mathrm{SF})-0.0002406 *(\Sigma 7 \mathrm{SF})^{2}+0.0661 *$ (age) where $\Sigma 7 \mathrm{SF}=$ the sum of the skin-fold thicknesses of pectoral, mid-axilla, triceps, subscapular, abdomen, suprailiacal, and front thigh mean skin-folds. ${ }^{28}$

Upon enrolling in the study the athletes were asked to maintain a comprehensive training diary recording all their training sessions, showing distance and duration, in the 3 months before the race. The training records included the weekly number of training sessions, showing duration, distance, and running speed, the weekly kilometers ran, the weekly hours ran, and the minimal and maximal kilometers ran per week. The athletes recorded their running speed during training in minutes $/ \mathrm{km}$. Additionally, they reported the number of years of active participation in running.

\section{Statistical analysis}

A power calculation was performed according to Gatsonis and Sampson. ${ }^{29}$ To achieve a power of $80 \%$ (two-sided Type I error of 5\%) to detect a minimal association between race time and anthropometric characteristics of $20 \%$ (ie, coefficient of determination $r^{2}=0.2$ ) a sample of 40 participants was required. Normally distributed data are presented as mean and standard deviation (SD). In a first step to reduce the number of predictor variables, the association of the variables of anthropometry, training and pre-race experience with total race time was investigated using bivariate correlation analysis. Given the multiple tests, Bonferroni correction was applied for $n=23$ variables $(P=0.002) .{ }^{30}$ In a second step, multiple linear regression analysis was used to further investigate the relationship of variables with significance in the bivariate analysis to race time. A probability value of less than 0.05 was accepted as significant for the multiple linear regression analysis. The best predictor variables were used to create an equation that could predict the half marathon race time. Bland-Altman analysis was used to determine absolute limits of agreement between predicted and effective race time. The coefficient of variation of performance $(\mathrm{CV} \%=100 \times \mathrm{SD} /$ mean) for race time was calculated.

\section{Results}

The 84 participants completed the half marathon distance within $103.9( \pm 16.5) \mathrm{min}(\mathrm{CV}=15.8 \%)$, running at a mean speed of $12.7( \pm 1.9) \mathrm{km} /$ hour. In the bivariate analysis using the age and the anthropometric measurements, body mass index, the skin-fold thicknesses at pectoral, mid-axilla, triceps, abdominal, suprailiacal, and medial calf site and percent body fat were related to half marathon race time (see Table 1). For the variables of experience and training, the

Table I Association between age, selected anthropometric and training variables with the half marathon race time for the 84 runners

\begin{tabular}{|c|c|c|}
\hline Anthropometric characteristics & Result & $\begin{array}{l}\text { Pearson's } \\
r\end{array}$ \\
\hline Age (years) & $40.6(10.2)$ & 0.29 \\
\hline Body mass (kg) & $76.2(8.4)$ & 0.29 \\
\hline Body stature (m) & $\mathrm{I} .78(0.07)$ & -0.21 \\
\hline Body mass index $\left(\mathrm{kg} / \mathrm{m}^{2}\right)$ & $23.8(2.1)$ & $0.56^{*}$ \\
\hline Pectoral skin fold (mm) & $9.3(4.2)$ & $0.48^{*}$ \\
\hline Mid-axilla skin fold (mm) & $10.4(4.6)$ & $0.42 *$ \\
\hline Triceps skin fold (mm) & $8.6(3.1)$ & $0.42 *$ \\
\hline Subscapular skin fold (mm) & II .5 (3.9) & 0.33 \\
\hline Abdominal skin fold (mm) & $19.1(9.3)$ & $0.4 I^{*}$ \\
\hline Suprailiac skin fold (mm) & $21.4(9.8)$ & $0.36^{*}$ \\
\hline Front thigh skin fold (mm) & $14.2(6.3)$ & 0.29 \\
\hline Medial calf skin fold (mm) & $6.4(2.4)$ & $0.53 *$ \\
\hline Sum of eight skin folds (mm) & $100.8(35.7)$ & 0.38 \\
\hline Body fat percentage (\%) & $17.7(4.6)$ & $0.49 *$ \\
\hline \multicolumn{3}{|l|}{ Training characteristics } \\
\hline Years as active runner & $8.1(8.9)$ & 0.02 \\
\hline Weekly distance ran (km) & $37.2(18.2)$ & $-0.57^{*}$ \\
\hline Minimal distance ran per week $(\mathrm{km})$ & $17.8(14.3)$ & $-0.47^{*}$ \\
\hline Maximal distance ran per week $(\mathrm{km})$ & $45.3(28.6)$ & $-0.50 *$ \\
\hline Hours ran per week (hour) & $4.6(6.3)$ & 0.16 \\
\hline $\begin{array}{l}\text { Number of running training } \\
\text { sessions per week }\end{array}$ & $3.1(1.2)$ & $-0.48 *$ \\
\hline $\begin{array}{l}\text { Distance per running } \\
\text { training session }(\mathrm{km})\end{array}$ & II.2(3.1) & $-0.37^{*}$ \\
\hline $\begin{array}{l}\text { Duration of running training } \\
\text { sessions (minute) }\end{array}$ & $62.8(13.4)$ & -0.19 \\
\hline $\begin{array}{l}\text { Speed of the training } \\
\text { sessions }(\mathrm{km} / \text { hour })\end{array}$ & $10.6(1.5)$ & $-0.54 *$ \\
\hline
\end{tabular}

Notes: Results are presented as mean (SD); *significant after Bonferroni correction $(P<0.002$ for 23 variables). 
weekly kilometers ran, the minimal and maximal distance ran per week, the number of running training sessions per week, the distance per running session, and the running speed of the training sessions were related to race time. When the significant anthropometric variables after bivariate analysis were inserted into a multivariate regression model, body mass index $(P=0.0097)$, both the suprailiacal $(P=0.044)$ and medial calf skin-fold thickness $(P=0.0350)$ were associated with half marathon race time $\left(r^{2}=0.45\right)$. For the training variables, running speed during training sessions $(P=0.0001)$ was related to race time after multivariate analysis $\left(r^{2}=0.47\right)$. When all significant variables of both anthropometry and training were inserted in a further multivariate regression model, body mass index and the speed of the training sessions (see Table 2) correlated to race time. Race time in a half marathon might be partially predicted by the following equation $\left(r^{2}=0.44\right)$ : Race time (minutes) $=72.91+3.045 *$ (body mass index, $\mathrm{kg} / \mathrm{m}^{2}$ ) $-3.884 \times$ (speed in running during training, $\mathrm{km} /$ hours) for recreational male runners. The predicted race time using this equation was 104.0 (10.4) minutes and correlated highly significantly to the achieved race time (see Figure 1). Figure 2 shows the level of agreement using Bland-Altman method (Bias $=-25.1 \pm 25.1$ minutes) between the effective and the predicted race time. Intra class correlation (ICC) between effective and predicted race time was 0.73 .

Skin-fold thicknesses with the exception of mid-axilla, triceps, and subscapular skin-fold and body fat were associated with both the weekly kilometers ran and the running speed during training (see Table 3). Weekly running hours were not related to skin-fold thicknesses and body fat.

\section{Discussion}

The first aim of this study was to investigate which basic variables of physical characteristics, training, and previous experience were related to the half marathon race time in recreational male runners. Based on the existing literature,

Table 2 Associations between significant characteristics of anthropometry and training with race time after multiple linear regression $(n=84)$

\begin{tabular}{llll}
\hline Variables & $\beta$ & SE & $P$-value \\
\hline Body mass index & 2.14 & 0.86 & 0.0150 \\
Suprailiac skin-fold & -0.02 & 0.18 & 0.8873 \\
Medial calf skin-fold & 1.80 & 0.84 & 0.0643 \\
Speed of the training session & -3.32 & 1.13 & 0.0045 \\
\hline
\end{tabular}

Notes: $\beta=$ regression coefficient; $S E$ = standard error of the regression coefficient; the coefficient of determination $\left(r^{2}\right)$ of the model was $44 \%$. Body mass index and speed of the training session were related to race time.

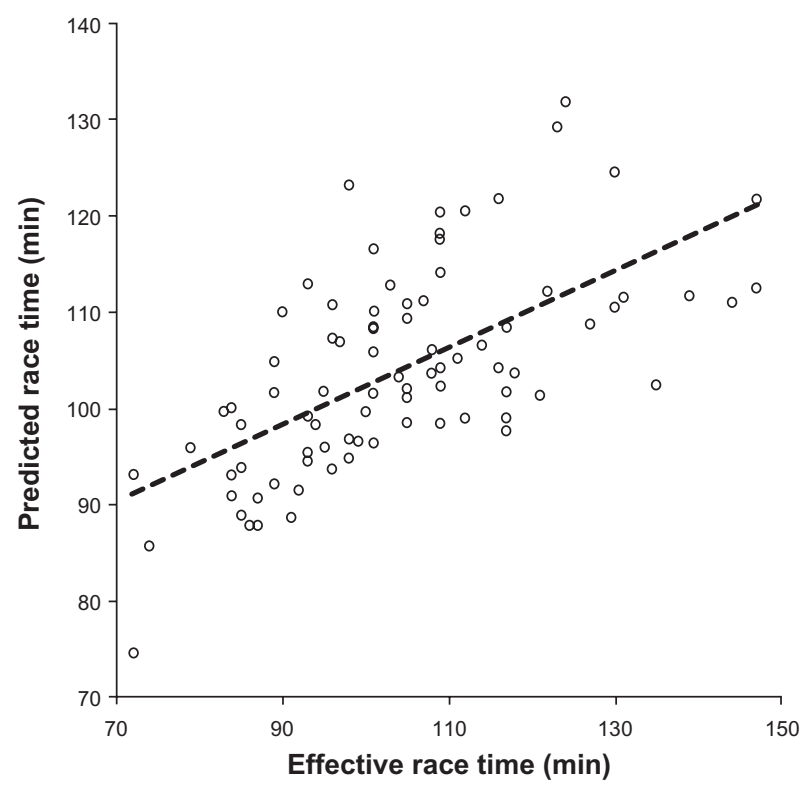

Figure I The predicted half marathon race time correlated significantly to the achieved half marathon race time $(n=84)(r=0.63, P<0.000 \mathrm{I})$.

it was hypothesized that variables of both anthropometry and training would be related to a half marathon race time, not only a single anthropometric characteristic such as a skin-fold thickness of the lower limbs. In accordance with our hypothesis, both body mass index as a variable of anthropometry and speed in running during the training sessions as a variable of training were related to the half marathon race time. Although skin-fold thicknesses of the lower limbs were related to running performance in elite athletes ${ }^{9}$, lower limb skin-fold thicknesses no longer appeared to be predictive in runners when corrected in a multivariate analysis with characteristics of training and previous experience..$^{31-33}$

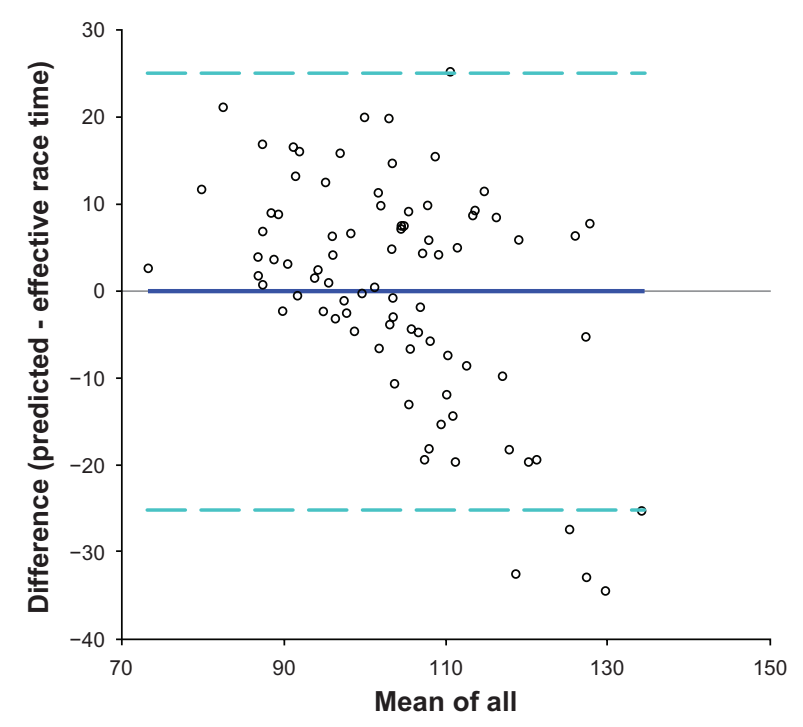

Figure 2 Bland-Altman plots comparing predicted with effective race time. 
Table 3 Association between skin-fold thicknesses and training variables

\begin{tabular}{llll}
\hline Variable & $\begin{array}{l}\text { Weekly kilometers ran } \\
\text { during training }\end{array}$ & $\begin{array}{l}\text { Weekly hours ran } \\
\text { during training }\end{array}$ & $\begin{array}{c}\text { Speed in running } \\
\text { during training }\end{array}$ \\
\hline Pectoral skin-fold & $-0.30, P=0.005 \mathrm{I}$ & 0.05 & $-0.31, P=0.0047$ \\
Mid-axilla skin-fold & -0.20 & 0.03 & $-0.33, P=0.0020$ \\
Triceps skin-fold & -0.18 & 0.02 & $-0.38, P=0.0003$ \\
Subscapular skin-fold & -0.18 & 0.06 & $-0.27, P=0.0143$ \\
Abdominal skin-fold & $-0.30, P=0.0055$ & 0.06 & $-0.37, P=0.0006$ \\
Suprailiac skin-fold & $-0.33, P=0.0023$ & 0.18 & $-0.28, P=0.0102$ \\
Front thigh skin-fold & $-0.35, P=0.0012$ & 0.06 & $-0.33, P=0.0023$ \\
Medial calf skin-fold & $-0.46, P<0.0001$ & 0.21 & $-0.42, P<0.0001$ \\
Sum of eight skin-folds & $-0.36, P=0.0008$ & -0.12 & $-0.37, P=0.0005$ \\
Percent body fat & $-0.33, P=0.0021$ & -0.12 & $-0.38, P=0.0004$ \\
\hline
\end{tabular}

Note: $P$-values are represented when the correlation analysis showed a significant relationship.

\section{Association of anthropometric measurements with the half marathon race time}

The main intention of our study was to find an association between skin-fold thicknesses and the half marathon race time in male recreational runners, as has been described for male high-level runners over $1500 \mathrm{~m}$ and 10,000 m. ${ }^{9}$ Arrese and Ostáriz reported significant and positive correlations between the front thigh and the medial calf skin-fold thickness with $1500 \mathrm{~m}$ and $10,000 \mathrm{~m}$ race times for elite male runners, but not for marathoners. ${ }^{9}$ We can confirm their findings that the calf skin-fold thickness was also significantly and positively related to running performance in these recreational male runners over the half-marathon distance after bivariate analysis, but not for the front thigh skin-fold. An explanation of these different findings could be that Arrese and Ostáriz did not include runners over the half marathon distance, but highly trained male runners over distances from $100 \mathrm{~m}$ to $10,000 \mathrm{~m}$ and the full marathon distance with a coefficient of variance (CV) in race performance for male marathoners of $2.19 \%$, drawn from the Top 50 sprinters and long-distance runners in Spain. ${ }^{9}$ In contrast, the present study was focused on recreational male runners who were much more heterogeneous over the half marathon distance $(\mathrm{CV}=15.8 \%)$.

In the multivariate analysis of the anthropometric measurements, body mass index and both the medial calf and the suprailiacal skin-fold thickness were also related to race time. The finding that the suprailiacal skin-fold thickness was related to half marathon race time might be due to the higher body mass index of these recreational runners compared to the elite runners of Arrese and Ostáriz. ${ }^{9}$ The body mass index in the 10,000 m runners of Arrese and Ostáriz was $20.06 \mathrm{~kg} / \mathrm{m}^{2}, 9$ which was considerably lower compared to the body mass index of $23.8 \mathrm{~kg} / \mathrm{m}^{2}$ in these recreational runners. Several studies have yielded a relationship between body mass, ${ }^{7,8,13-15}$ body mass index,,${ }^{11,14,16,22,34}$ body fat, ${ }^{11,14,17,22}$ and performance for long distance runners. In the present study, both percent body fat and body mass index were also significantly related to the half marathon race time in the bivariate analysis. However, in the multivariate analysis, body fat remained no longer a significant predictor variable of anthropometry. We must assume that skin-fold thicknesses and percent body fat are of lesser importance than body mass index for recreational male runners than it is for elite runners.

\section{Association of training variables with the half marathon race time}

For marathoners, the number of training session days, the number of total training sessions, the total kilometers covered during a training session, the mean number of kilometers covered per training session, the longest mileage covered per training session, the total of training minutes, the maximal kilometers ran per week, the mean kilometers covered per week, and the mean kilometers covered per day were related to the marathon race time. ${ }^{19,22,23}$ For the recreational male half marathoners in this study, the weekly kilometers ran, the minimal and maximal distance ran per week, the hours ran per week, the number of running training sessions per week, and the running speed of the training sessions were related to the half marathon race time after bivariate analysis. In the multivariate analysis, however, only the running speed during training remained significant. Also, when controlled for the anthropometric measurements, the running speed during the training sessions remained the single predictor training variable. Additionally, for runners of distances less than a half marathon, the training speed was associated with performance. In 10,000 m runners, high-intensity training 
was related to performance, ${ }^{35}$ and in distance runners the peak running velocity over $5000 \mathrm{~m}$ was highly predictive of the distance running performance. ${ }^{24} \mathrm{We}$ must assume that the intensity in training is more important than the volume for a fast race time in a half marathon.

\section{Association of training variables with anthropometric characteristics}

The second aim was to investigate potential associations between skin-fold thicknesses and training characteristics such as volume and running speed. Based upon previous studies of runners up to the marathon distance, an association between lower body skin-fold thicknesses and variables of training might be expected. Legaz and Eston described in a sample of 24 male and female endurance runners a significant association between the decrease in front thigh skin-fold thickness and improvement in performance due to training $(r=-0.74, P<0.001) .{ }^{10} \mathrm{We}$ found an association of skin-fold thicknesses and body fat with both weekly running kilometers and running speed during training. However, skin-fold thickness at mid-axilla, triceps, and subscapular were not associated with weekly running kilometers. In addition, weekly running hours were not related to skinfold thicknesses and body fat. Nonetheless, we can confirm the findings of Legaz and Eston that anthropometric and training characteristics are related.$^{10}$ However, a decrease in skin-fold thickness during training might also be due to diet. Regarding the present results, future novice half marathoners should rather focus on a fast running speed during training since all skin-fold thicknesses were related to running speed in training, but not all skin-fold thicknesses were associated with weekly kilometers ran.

\section{Strength, limitations, and implications for future research}

The principal strength of this study is that little information about half marathon performance on recreational runners exists and this study provides data to the literature for half marathoners. A cross-sectional study is, however, limited regarding the influence and effects of anthropometry and training on race time in runners, since only an intervention trial can answer this question. Other limitations are the lack of fitness evaluation of these athletes. We focused this investigation on anthropometry, pre-race experience, and training. Other aspects such as somatotype of the athlete, nutrition, and influence of environment were not considered. Unfortunately we have no data about energy deficit, or disorder in fluid or electrolyte metabolism which also might affect endurance performance. The rather small correlation coefficient in the equation might be due to the fact that we did not include physiological characteristics such as critical power, ${ }^{36}$ running velocity at the lactate turnpoint, ${ }^{37}$ treadmill velocity, ${ }^{38}$ or the running speed at lactate threshold and maximum lactate steady state. ${ }^{39}$ In a recent laboratory study using twelve subjects, the velocity at both lactate threshold and maximum lactate steady state explained $85 \%$ and $87 \%$ of the variance in running performance. ${ }^{39}$ However, to investigate more than 80 recreational half marathoners in a laboratory before a race is impossible due to logistical reasons. As an alternative, a field test could be performed to estimate maximum oxygen uptake. ${ }^{40}$

\section{Conclusion}

To summarize, both variables of anthropometry and training predict a half marathon race time in recreational male runners and cannot be reduced to one single predictor variable such as skin-fold thicknesses. The thicknesses of skin-folds and body fat showed no association with half marathon race time after multivariate analysis, and running speed during training seems to be more important than volume. For future novice male half marathoners intending to start for the first time in a half marathon, race time might be partially predicted by the following equation $\left(r^{2}=0.44\right)$ : Race time (minutes) $=72.91+3.045 *$ (body mass index, $\left.\mathrm{kg} / \mathrm{m}^{2}\right)-3.884 *$ (speed in running during training, $\mathrm{km} /$ hour). Future studies should include physiological variables in order to increase the correlation coefficient of an equation to predict a half marathon race time for recreational male runners.

\section{Acknowledgment}

We thank Mary Miller for her help in translation.

\section{Disclosure}

The authors have no conflicts of interest in this work.

\section{References}

1. Marti B, Abelin T, Minder CE. Relationship of training and life-style to 16-km running time of 4000 joggers. The '84 Berne "Grand-Prix" Study. Int J Sports Med. 1988;9:85-91.

2. Nettleton S, Hardey M. Running away with health: the urban marathon and the construction of 'charitable bodies'. Health (London). 1996;10: 441-460.

3. Anderson T. Biomechanics and running economy. Sports Med. 1996; 22:76-89.

4. Morgan DW, Martin PE, Krahenbuhl GS. Factors affecting running economy. Sports Med. 1989;7:310-330.

5. Pate RR, Macera CA, Bailey SP, Bartoli WP, Powell KE. Physiological, anthropometric, and training correlates of running economy. Med Sci Sports Exerc. 1992;24:1128-1133. 
6. Saunders PU, Pyne DB, Telford RD, Hawley JA. Factors affecting running economy in trained distance runners. Sports Med. 2004;34:

7. Hagan RD, Smith MG, Gettman LR. Marathon performance in relation to maximal aerobic power and training indices. Med Sci Sports Exerc. 1981;13:185-189.

8. Bale P, Bradbury D, Colley E. Anthropometric and training variables related to 10-km running performance. Br J Sports Med. 1986;20: $170-173$.

9. Arrese AL, Ostariz ES. Skinfold thicknesses associated with distance running performance in highly trained runners. J Sports Sci. 2006;24: 69-76.

10. Legaz A, Eston R. Changes in performance, skinfold thicknesses, and fat patterning after three years of intense athletic conditioning in high level runners. Br J Sports Med. 2005;39:851-856.

11. Knechtle B, Knechtle P, Rosemann T. Similarity of anthropometric measures for male ultra-triathletes and ultra-runners. Percept Mot Skills. 2010;111:805-818.

12. Knechtle B, Knechtle P, Rosemann T, Senn O. What is associated with race performance in male $100-\mathrm{km}$ ultra-marathoners-anthropometry, training or marathon best time? J Sports Sci. 2011;29:571-577.

13. Kenney WL, Hodgson JL. Variables predictive of performance in elite middle-distance runners. Br J Sports Med. 1985;19:207-209.

14. Knechtle B, Knechtle P, Rosemann T, Lepers R. Predictor variables for a $100-\mathrm{km}$ race time in male ultra-marathoners. Percept Mot Skills. 2010;111:681-693.

15. Knechtle B, Duff B, Welzel U, Kohler G. Body mass and circumference of upper arm are associated with race performance in ultraendurance runners in a multistage race - the Isarrun 2006. Res Q Exerc Sport. 2009;80:262-268.

16. Hoffman MD, Lebus DK, Ganong AC, Casazza GA, Van Loan M. Body composition of 161-km ultramarathoners. Int J Sports Med. 2010;31: 106-109.

17. Hoffman MD. Anthropometric characteristics of ultramarathoners. Int J Sports Med. 2008;29:808-811.

18. Knechtle B, Knechtle P, Schulze I, Kohler G. Upper arm circumference is associated with race performance in ultra-endurance runners. $\mathrm{Br} J$ Sports Med. 2008;42:295-299

19. Yeung SS, Yeung EW, Wong TW. Marathon finishers and non-finishers characteristics: a preamble to success. J Sports Med Phys Fitness. 2001; 41:170-176.

20. Bale P, Rowell S, Colley E. Anthropometric and training characteristics of female marathon runners as determinants of distance running performance. J Sports Sci. 1985;3:115-126.

21. Scrimgeour AG, Noakes TD, Adams B, Myburgh K. The influence of weekly training distance on fractional utilization of maximum aerobic capacity in marathon and ultramarathon runners. Eur J Appl Physiol. 1986;55:202-209.

22. Hagan RD, Upton SJ, Duncan JJ, Gettman LR. Marathon performance in relation to maximal aerobic power and training indices in female distance runners. Br J Sports Med. 1987;21:3-7.

23. Hewson DJ, Hopkins WG. Specifity of training and its relation to the performance of distance runners. Int J Sports Med. 1996;17:199-204. $465-485$

24. Scott BK, Houmard JA. Peak performance velocity is highly related to distance running performance. Int J Sports Med 1994;15:504-507.

25. Voight AM, Roberts WO, Lunos S, Chow LS. Pre- and postmarathon training habits of nonelite runners. Open Access J Sports Med. 2011; 2:13-18.

26. Becque MD, Katch VL, Moffatt RJ. Time course of skin-plus-fat compression in males and females. Hum Biol. 1986;58:33-42.

27. Knechtle B, Joleska I, Wirth A, Knechtle P, Rosemann T, Senn O. Intra- and inter-judge reliabilities in measuring the skin-fold thicknesses of ultra runners under field conditions. Percept Mot Skills. 2010;111: 105-106.

28. Ball SD, Altena TS, Swan PD. Comparison of anthropometry to DXA, new prediction equation for men. Eur J Clin Nutr. 2004;58: 1525-1531.

29. Gatsonis C, Sampson AR. Multiple correlation: exact power and sample size calculations. Psychol Bull. 1989;106:516-524.

30. Abdi, H. Bonferroni and Šidák corrections for multiple comparisons. In Salkind NJ, editor. Encyclopedia of measurement and statistics. Thousand Oaks, CA: Sage; 2007.

31. Knechtle B, Knechtle P, Rüst CA, Rosemann T. Leg skinfold thicknesses and race performance in male 24-hour ultra-marathoners. Proc (Bayl Univ Med Cent). 2011;24:110-114.

32. Knechtle B, Knechtle P, Rosemann T, Lepers R. Personal best marathon time and longest training run, not anthropometry, predict performance in recreational 24-hour ultrarunners. J Strength Cond Res. 2011. [Epub ahead of print].

33. Knechtle B, Wirth A, Knechtle P, Zimmermann K, Kohler G. Personal best marathon performance is associated with performance in a 24-h run and not anthropometry or training volume. Br J Sports Med. 2009; 43:836-839.

34. Lucia A, Esteve-Lanao J, Oliván J, et al. Physiological characteristics of the best Eritrean runners' exceptional running economy. Appl Physiol Nutr Metab. 2006;31:530-540.

35. Billat V, Lepretre PM, Heugas AM, Laurence MH, Salim D, Koralsztein JP. Training and bioenergetic characteristics in elite male and female Kenyan runners. Med Sci Sports Exerc. 2003;35:297-304.

36. Kolbe T, Dennis SC, Selley E, Noakes TD, Lambert MI. The relationship between critical power and running performance. J Sports Sci. 1995; 13:265-269.

37. Noakes TD, Myburgh KH, Schall R. Peak treadmill running velocity during the $\mathrm{VO}_{2}$ max test predicts running performance. J Sports Sci. 1990;8:35-45.

38. Stratton E, O'Brien BJ, Harvey J, et al. Treadmill velocity best predicts 5000-m run performance. Int J Sports Med. 2009;30:40-45.

39. Tolfrey K, Hansen SA, Dutton K, McKee T, Jones AM. Physiological correlates of 2-mile run performance as determined using a novel ondemand treadmill. Appl Physiol Nutr Metab. 2009;34:763-772.

40. Flouris AD, Metsios GS, Famisis K, Geladas N, Koutedakis Y. Prediction of $\mathrm{VO}_{2}$ max from a new field test based on portable indirect calorimetry. J Sci Med Sport. 2010;13:70-73.

\section{Dovepress}

\section{Publish your work in this journal}

Open Access Journal of Sports Medicine is an international, peer-reviewed, open access journal publishing original research, reports, reviews and commentaries on all areas of sports medicine. The manuscript management system is completely online and includes a very quick and fair peer-review system.

Visit http://www.dovepress.com/testimonials.php to read real quotes from published authors. 